\title{
Liposomal Docetaxel
}

National Cancer Institute

\section{Source}

National Cancer Institute. Liposomal Docetaxel. NCI Thesaurus. Code C92581.

A formulation of the poorly soluble, semi-synthetic, second-generation taxane docetaxel encapsulated within liposomes, with antineoplastic activity. Upon intravenous administration, docetaxel binds to and stabilizes tubulin, thereby inhibiting microtubule disassembly which results in cell-cycle arrest at the G2/M phase and cell death. This liposomal formulation solubilizes docetaxel without the use of toxic solvents such as Tween 80, permitting the administration of larger doses of docetaxel while avoiding solvent-associated toxicity, including hypersensitivity reactions. In addition, liposomal delivery of docetaxel improves drug penetration into tumors and decreases drug clearance, thereby increasing the duration of therapeutic drug effects while lowering the toxicity profile. 